\title{
On the benefit of galls of Quercus brantii Lindl. in murine colitis: the role of free gallic acid
}

\author{
Mahnaz Khanavi ${ }^{1}$, Mansoureh Sabbagh-Bani-Azad ${ }^{1}$, Amir Hossein Abdolghaffari ${ }^{2,3}$, Mahdi Vazirian ${ }^{1}$, \\ Isa Isazadeh ${ }^{1}$, Mohammad Amin Rezvanfar ${ }^{4}$, Maryam Baeeri ${ }^{4}$, Azadeh Mohammadirad4, \\ Roja Rahimi ${ }^{1,5}$, Mohammad Reza Shams-Ardekani ${ }^{1,5}$, Mohammad Abdollahi ${ }^{4}$
}

\author{
${ }^{1}$ Department of Pharmacognosy, Faculty of Pharmacy, and Medicinal Plants Research \\ Center, Tehran University of Medical Sciences (TUMS), Tehran, Iran \\ 2Pharmacology and Applied Medicine, Department of Medicinal Plants Research \\ Center, Institute of Medicinal Plants, ACECR, Karaj, Iran \\ ${ }^{3}$ International Campus, Tehran University of Medical Sciences, Tehran, Iran \\ ${ }^{4}$ Department of Pharmacology and Toxicology, Faculty of Pharmacy, and \\ Pharmaceutical Sciences Research Center, Tehran University of Medical Sciences, \\ Tehran, Iran \\ ${ }^{5}$ Faculty of Traditional Iranian Medicine, Tehran University of Medical Sciences, \\ Tehran, Iran
}

Submitted: 23 August 2012

Accepted: 26 November 2012

Arch Med Sci 2014; 10, 6: 1225-1234

DOI: 10.5114/aoms.2014.47831

Copyright $\odot 2014$ Termedia \& Banach

\section{Abstract}

Introduction: In this study we investigated the effect of gall of Quercus brantii Lindl., a traditional Iranian medicine, in a murine model of experimental colitis induced in male rats by rectal administration of 2,4,6-trinitrobenzene sulfonic acid (TNBS).

Material and methods: Quantification of the main active components was done for estimation of total phenolic content and free gallic acid. Gall of Quercus brantii Lindl. in two forms (gall powder and gall hydro alcoholic extract) was gavaged for 10 days $(500 \mathrm{mg} / \mathrm{kg}$ ). Ten days after induction of colitis, colonic status was examined by macroscopic, microscopic and biochemical analyses. Colonic tumor necrosis factor- $\alpha$ (TNF- $\alpha$ ) and interleukin-1 $\beta$ (IL-1 $\beta$ ) were analyzed as biomarkers of inflammatory condition. To determine the role of oxidative stress (OS) in colitis, the levels of cellular lipid peroxidation (LPO), total antioxidant power (TAP) and myeloperoxidase (MPO) were measured in colon tissues.

Results: TNBS-induced colitis exhibited a significant increase in colon MPO activity and concentrations of cellular LPO, TNF- $\alpha$ and IL-1 $\beta$, while TAP was significantly reduced. Microscopic evaluations of the colonic damage in the colitis group revealed multifocal degenerative changes in the epithelial lining and areas of necrosis, extensive mucosal and sub-mucosal damage with congested blood vessels, edema and hemorrhages along with extensive infiltration of inflammatory cells. Parameters including macroscopic and microscopic scores, TNF- $\alpha$, IL-1 $\beta$, LPO, TAP and MPO improved by both gall extract and gall powder of Quercus brantii Lindl. and reached close to normal levels. The level of total phenols (GAE/100 g of sample) and free gallic acid were estimated to be $88.43 \pm 7.23$ (mean \pm SD) and $3.74 \%$ of dry weight, respectively.

Conclusions: The present study indicates that the gall of Quercus brantii Lindl. is able to exert antioxidative and anti-inflammatory effects on the biochemical and pathological parameters of colitis.

Key words: colitis, oxidative stress, Quercus brantii Lindl., animal.
Corresponding author: Prof. Mohammad Abdollahi Faculty of Pharmacy and Pharmaceutical Sciences Research Center

Tehran University of Medical Sciences Tehran 1417614411, Iran Phone/fax: +982166959104 E-mail: mohammad. abdollahi@utoronto.ca 


\section{Introduction}

Inflammatory bowel disease (IBD), including Crohn's disease (CD) and ulcerative colitis (UC), is one of the chronic disorders of the gastrointestinal tract with an immuno-inflammatory origin. Recent studies have confirmed involvement of some pathological elements and beneficial effects of their inhibitors or activators such as growth factors and nitric oxide [1-3], inflammatory cytokines such as prostaglandins $[4,5]$ or tumor necrosis factor (TNF) [6-8], immunoregulators [9-11], oxidative stress [12], microbes [13-16], probiotics, potassium channel openers [17], adenosine triphosphate (ATP) donors [18], and phosphodiesterase inhibitors (PDEls) [19-21] in IBD. Most of the synthetic drugs for management of IBD have serious adverse effects that led researchers to work on complementary and alternative remedies that can induce marginal remission in disease activity $[22,23]$.

Quercus brantii Lindl., belonging to the family of Fagaceae, is a small tree with galls arising on its young branches as a result of attack by the gall wasp Adleria gallae-tinctoria [24]. This herb is endemic in Lorestan and Kordestan provinces of Iran. The major components of galls are tannins, gallic acid, syringic acid, ellagic acid, $\beta$-sitosterol, amentoflavone, hexamethyl ether, isocryptomerin, methyl betulate, and hexagalloyl glucose [25].

Quercus brantii galls (locally called 'mazoo') are famous in traditional Iranian medicine for treating chronic diarrhea and many diseases, with or without inflammatory pathogenesis [26]. Regarding its great medicinal value, Quercus galls have been reported to have the following pharmacological actions: astringent, anti-pyretic, anti-parkinsonism [25], anti-tremorine, local anesthetic, central nervous system (CNS) depressant, analgesic [25, 27], anti-diabetic [25, 28], anti-bacterial [29-34], anti-oxidant [35, 36] and anti-inflammatory [25].

Therefore, the above knowledge led us to examine the beneficial effects of $Q$. brantii in a murine model of colitis to understand the mechanisms by which this herb might act. Quantification of the main active components was done for estimation of total phenolic content and free gallic acid.

\section{Material and methods}

\section{Chemicals}

2,4,6-Trinitrobenzene sulfonic acid (TNBS) and rhodanine from Sigma-Aldrich Chemie $(\mathrm{GmbH}, \mathrm{Mu}$ nich, Germany), thiobarbituric acid (TBA), trichloroacetic acid (TCA), n-butanol, hexadecyl trimethyl ammonium bromide (HETAB), 2,4,6-tri (2-pyridyl)-s-triazine (TPTZ), diphenyl-2-picryl hydrazyl (DPPH), methanol, butyl hydroxy anisol (BHA), hydrochloric acid $(\mathrm{HCl})$, malondialdehyde (MDA), ethylenediamine tetra-acetic acid (EDTA), O-di- anisidine hydrochloride, hydrogen peroxide, acetic acid, sodium acetate, Coomassie reagent, bovine serum albumin (BSA), ferric chloride $\left(\mathrm{FeCl}_{3} \cdot 6 \mathrm{H}_{2} \mathrm{O}\right)$, sodium sulfate $\left(\mathrm{Na}_{2} \mathrm{SO}_{4}\right)$, sulfuric acid $\left(\mathrm{H}_{2} \mathrm{SO}_{4}\right)$, phosphoric acid $\left(\mathrm{H}_{3} \mathrm{PO}_{4}\right)$, potassium dihydrogen phosphate $\left(\mathrm{KH}_{2} \mathrm{PO}_{4}\right)$, potassium hydrogen diphosphate $\left(\mathrm{K}_{2} \mathrm{HPO}_{4}\right)^{2}$, peroxide hydrogen $\left(\mathrm{H}_{2} \mathrm{O}_{2}\right)$, sodium carbonate $\left(\mathrm{Na}_{2} \mathrm{CO}_{3}\right)$, Na-K-tartrate, cupric sulfate $\left(\mathrm{CuSO}_{4} \cdot 5 \mathrm{H}_{2} \mathrm{O}\right)$, Folin-Ciocalteu reagent and Gallic acid from Merck (Germany), rat-specific tumor necrosis factor- $\alpha$ (TNF- $\alpha$ ) and interleukin- $1 \beta$ (IL-1 $\beta)$ ELISA kits from Bender MedSystems (Austria), and dexamethasone and vitamin E from the local Pharmaceutical Co. (Tehran) were used in this study.

\section{Plant material}

The galls of Quercus brantii Lindl. were collected from the Koohdasht region in the Lorestan province, Iran, in September 2010, and were ground well. A voucher specimen was preserved in the Herbarium of the Department of Pharmacognosy, Faculty of Pharmacy, Tehran University of Medical Science (TUMS), Tehran, Iran (No. 6730-TEH).

\section{Extraction and preparation}

The dried gall of $Q$. brantii was finely powdered by milling. The extract was prepared using $30 \mathrm{~g}$ of powder of the gall with a mixture of methanol/ water (50:50) (21.8 g dry weight corresponding to $73 \% \mathrm{w} / \mathrm{w})$.

\section{In vitro diphenyl-2-picryl hydrazyl free radical scavenging activity}

The free radical scavenging activity of galls was measured by a DPPH scavenging assay using a previously described method [37]. This test was done to estimate the best antioxidant dose of Q. brantii galls. In this regard the extract was prepared in four concentrations: 100, 300, 500 and $1000 \mu \mathrm{g} / \mathrm{ml}$. A DPPH is one of a few stable and organic nitrogen radicals and has a maximum absorption at $517 \mathrm{~nm}$. Upon reduction, the solution color changes from blue to yellow. The decrease in absorbance at $517 \mathrm{~nm}$ was determined after $5 \mathrm{~min}$ and then the free radical scavenging activity was calculated.

\section{Estimation of total phenolic content}

The Folin-Ciocalteu method [38] was used to determine total phenolic content. One $\mathrm{ml}$ of sample extract $(100 \mu \mathrm{g} / \mathrm{ml}$ in methanol) was mixed with $1.5 \mathrm{ml}$ of $0.2 \mathrm{~N}$ Folin-Ciocalteu reagent. Then, $1.5 \mathrm{ml}$ of sodium bicarbonate solution $(75 \mathrm{~g} / \mathrm{l})$ was added to the mixture, and after 30 min the absorbance was measured at $765 \mathrm{~nm}$ against a metha- 
nol blank. The calibration curve was produced using standard gallic acid. The means of three tests in the 3 following days were reported as gallic acid equivalent (GAE)/100 $\mathrm{g}$ of the sample.

\section{Quantification of free gallic acid}

Rhodanine assay [39] was used for quantitation of free gallic acid. One hundred $\mathrm{mg}$ of sample was extracted by $10 \mathrm{ml}$ of acetone (70\%) in an ultrasonic water bath for $20 \mathrm{~min}$ at room temperature. After centrifugation for $10 \mathrm{~min}$ at $3000 \mathrm{~g}$ (the contents were cooled by keeping the tubes on ice before centrifugation), $200 \mu$ l of supernatant was pipetted in a test tube (4 tubes were prepared). Acetone was removed from samples and then $200 \mu$ of $0.2 \mathrm{~N}$ sulfuric acid was added. To three tubes, $300 \mu$ of the rhodanine solution $(0.667 \%$ $\mathrm{w} / \mathrm{v}$ in methanol) and to the fourth (blank) $300 \mu \mathrm{l}$ of methanol were added. After $5 \mathrm{~min}, 200 \mu \mathrm{l}$ of $0.5 \mathrm{~N} \mathrm{KOH}$ solution was added to all the tubes and then, $2.5 \mathrm{~min}$ later, $4.3 \mathrm{ml}$ of distilled water was added and the absorbance was read after $15 \mathrm{~min}$ at $520 \mathrm{~nm}$ against an appropriate blank. Four different concentrations of gallic acid (4-20 $\mu \mathrm{g} / 5 \mathrm{ml})$ were prepared to produce the calibration curve. Each assay was done in triplicate and the data were expressed as mean \pm SD.

\section{In vivo study}

Male Wistar-albino rats, weighing between $220 \mathrm{~g}$ and $230 \mathrm{~g}$, were used in this study. Animals were maintained under standard conditions of temperature $\left(23 \pm 1^{\circ} \mathrm{C}\right)$, relative humidity (55 $\pm 10 \%)$, and a $12 / 12 \mathrm{~h}$ light/dark cycle, and fed with a standard pellet diet and water ad libitum. They were housed individually in standard polypropylene cages with a wire mesh top. All ethical themes of the studies on animals were considered carefully and the experimental protocol was approved by the Ethical Committee of TUMS with the code number 89-03-33-11232.

Before starting the whole project, acute toxicity of $Q$. brantii galls was tested. For this, rats were fed with several doses of the gall extract and gall powder and observed for $48 \mathrm{~h}$. It was found that up to $2000 \mathrm{mg} / \mathrm{kg}$ of gall extract and $2740 \mathrm{mg} /$ $\mathrm{kg}$ of gall powder are not toxic and thus they are categorized as practically non-toxic [40].

At the next step, 30 male rats were randomly divided into five groups randomly containing 6 in each group. Colitis was induced by instillation of TNBS in 4 groups and the resting group was considered as a sham group that received normal saline instead of TNBS. The four groups receiving TNBS were: 1 - control group that received no treatment; 2 - dexamethasone treated group (Dexa) receiving dexamethasone as a positive standard $(1 \mathrm{mg} / \mathrm{kg}) ; 3$ - gall extract treated group (Extract) receiving extract of $Q$. brantii galls $(500 \mathrm{mg} / \mathrm{kg}$; the best antioxidant activity of galls of $Q$. brantii was achieved with concentration of $500 \mu \mathrm{g} / \mathrm{ml}$ according to the DPPH test result; Figure 1); and 4 - gall powder treated group (Powder) receiving gall powder in the form of a suspension $(685 \mathrm{mg} / \mathrm{kg}$; each $100 \mathrm{~g}$ of gall powder is equivalent to $73 \mathrm{~g}$ of extract).

Dexamethasone was administered intraperitoneally, and gall extract and gall powder were administered by gavage for 10 days. The day of induction of colitis was considered as the first day.

All the rats were fasted for $36 \mathrm{~h}$ before induction of colitis. They were deprived of food but were allowed free access to tap water. After this, rats were anesthetized with administration of $50 \mathrm{mg} /$ $\mathrm{kg}$ pentobarbital sodium intraperitoneally. They were positioned on their right side, and $0.3 \mathrm{ml}$ of a mixture containing 6 volumes of TNBS $5 \% \mathrm{w} / \mathrm{v}$ in water (equal to $15 \mathrm{mg}$ TNBS) plus 4 volumes of ethanol (99\%) was instilled through the rectum using a rubber cannula ( $8 \mathrm{~cm}$ long) [41]. Then, rats were maintained in a supine Trendelenburg position in order to prevent anal leakage of TNBS. Rats were treated in the next 10 days. On the $11^{\text {th }}$ day, all the animals were sacrificed using an overdose of ether inhalation. The abdomen was rapidly dissected open and the colon was removed. The pieces of colon were cut open in an ice bath, cleaned gently using normal saline, and observed normally for macroscopic changes and scored as described later. Then samples were cut into two pieces, one piece for histopathology assessment (maintained in $5 \mathrm{ml}$ formalin $10 \%$ as fixative) and one piece for measuring biomarkers. The pieces for analysis of biomarkers were weighed and maintained at $-20^{\circ} \mathrm{C}$ for $24 \mathrm{~h}$. Then, the colonic samples were homogenized in 10 volumes of ice cold potassium phosphate buffer $(50 \mathrm{mM}, \mathrm{pH} 7.4)$, sonicated and centrifuged for $30 \mathrm{~min}$ at $3500 \mathrm{~g}$. The superna-

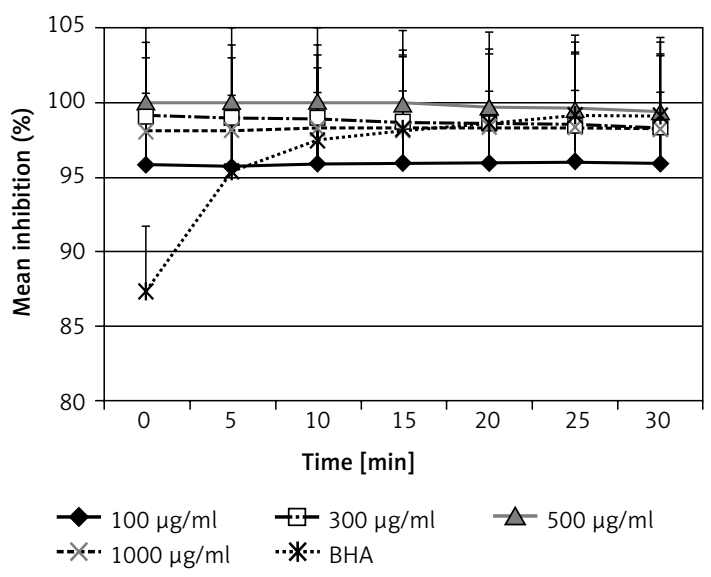

Figure 1. The DPPH radical scavenging activity of the Q. brantii extract. Each experiment was performed at least three times and data are expressed as averages. The BHA was used as a control 
tants were transferred to several microtubes for separate biochemical assays and all were kept at $-80^{\circ} \mathrm{C}$ until analyses.

\section{Macroscopic and microscopic assessment of colonic damage}

The severity of colonic damage was evaluated using the colon macroscopic scoring system, which takes into account the area of inflammation and presence/absence of ulcers: 0 (normal appearance with no damage), 1 (localized hyperemia without ulceration), 2 (linear ulceration without significant inflammation), 3 (linear ulceration with inflammation at one site), 4 (two or more sites of ulceration extending more than $1 \mathrm{~cm}$ along the length of the colon), and 5-8 (damage extending more than $2 \mathrm{~cm}$ along the length of colon and the score is enhanced by 1 for each increased $\mathrm{cm}$ of involvement) [42]. In addition, for microscopic analysis, the fixed segments in formalin 10\% were embedded in paraffin and stained with hematoxylin and eosin. The scoring was performed by an expert cytohistopathologist blind to the treated groups. Microscopic scores were determined as follows: 0 (no damage), 1 (focal epithelial edema and necrosis), 2 (disperse swelling and necrosis of the villi), 3 (necrosis with neutrophil infiltration in submucosa), 4 (widespread necrosis with massive neutrophil infiltration and hemorrhage) as described previously [17].

\section{Determination of TNF- $\alpha$ and IL-1 $\beta$}

Quantitative detection of TNF- $\alpha$ and IL-1 $\beta$ levels in colon tissues were evaluated using an enzyme-linked immunosorbent assay rat-specific ELISA kit as instructed by the kit brochure. The absorbance of the final colored product was measured at $450 \mathrm{~nm}$ as the primary wavelength and $620 \mathrm{~nm}$ as the reference wavelength. TNF- $\alpha$ and IL-1 $\beta$ levels were expressed as $\mathrm{pg} / \mathrm{mg}$ protein of tissue as described previously [43].

\section{Total ferric reducing antioxidant power (FRAP) assay}

Total antioxidant power of colon was evaluated by measuring the ability to reduce $\mathrm{Fe}^{3+}$ to $\mathrm{Fe}^{2+}$. Interaction of TPTZ with $\mathrm{Fe}^{2+}$ results in formation of a blue color, with maximum absorbance at $593 \mathrm{~nm}$. Data were expressed as $\mu \mathrm{M}$ ferric ions reduced to ferrous per $\mathrm{mg}$ protein. Details were described previously [44].

\section{Myeloperoxidase (MPO) activity measurement}

About $0.1 \mathrm{ml}$ of supernatant was combined with $2.9 \mathrm{ml}$ of $50 \mathrm{mM}$ phosphate buffer containing $0.167 \mathrm{mg} / \mathrm{ml}$ o-dianisidine hydrochloride and
$0.0005 \% \mathrm{H}_{2} \mathrm{O}_{2}$. The change in absorbance was measured spectrophotometrically at $460 \mathrm{~nm}$ for $3 \mathrm{~min}$. One unit of MPO activity is described as the change in absorbance per min at room temperature, in the final reaction. The details of the procedure have been previously described [45].

\section{Lipid peroxide thiobarbituric acid-reactive} substance (TBARS) assay

Level of lipid peroxidation was assessed in colon tissue using the thiobarbituric acid-reactive substance (TBARS) assay as described in detail previously [46]. Data were reported as $\mu \mathrm{g} / \mathrm{mg}$ protein.

\section{Total protein}

Total protein (TP) of colon was measured according to the Bradford method. The BSA was used as a standard and results were reported as $\mathrm{mg} / \mathrm{ml}$ of homogenized colon [47].

\section{Statistical analysis}

Data were analyzed by StatsDirect 2.7.8. Oneway ANOVA followed by Tukey's post hoc test for multiple comparisons were used. Values of $p$ less than 0.05 were considered significant. Results are expressed as mean \pm standard error of the mean (SEM).

\section{Results \\ DPPH}

The in vitro evaluation of antioxidant effects of Q. brantii is shown in Figure 1.

The antioxidant power of $Q$. brantii did not change with time in 30 min in comparison to $\mathrm{BHA}$, which increased from 87.3 to 99.08 in $30 \mathrm{~min}$. Antioxidant level of the extract increased in a dose-dependent manner up to $500 \mu \mathrm{g} / \mathrm{ml}$ concentration, but this was not significant.

\section{Total phenolic content}

The level of total phenols (GAE/100 g of sample) was estimated to be $88.43 \pm 7.23$ (mean \pm SD) using the standard curve of gallic acid (Table I) $(y=$ $\left.0.0074 x-0.0756, R^{2}=0.9858\right)$. Therefore the total phenol content received in the $4^{\text {th }}$ group (treated with gall powder) was $605.75 \pm 49.53 \mathrm{mg} / \mathrm{kg} \mathrm{GAE}$.

\section{Free gallic acid content}

The calibration curve of gallic acid was linear over the range $(4-20 \mu \mathrm{g} / 5 \mathrm{ml})\left(R^{2}=0.9935\right)$. The result showed that the amount of free gallic acid in powdered galls was $3.74 \%$ of dry weight. Therefore the amount of free gallic acid received in the $4^{\text {th }}$ group (treated with $685 \mathrm{mg} / \mathrm{kg}$ gall powder) was $25.62 \mathrm{mg} / \mathrm{kg}$. 
Table I. Total phenolic content of galls of Quercus brantii Lindl.

\begin{tabular}{|lcccccc|}
\hline Day & \multicolumn{3}{c}{ Absorption [nm] } & \multicolumn{3}{c|}{ Phenolic content (GAE/100 g) } \\
\hline 1 & 0.584 & 0.608 & 0.651 & 89.14 & 92.38 & 98.18 \\
\hline 2 & 0.490 & 0.583 & 0.634 & 76.43 & 89.00 & 95.89 \\
\hline 3 & 0.509 & 0.553 & 0.597 & 79.00 & 84.95 & 90.89 \\
\hline Sum, mean \pm SD & & $0.579 \pm 0.053$ & & & $88.43 \pm 7.23$ & \\
\hline
\end{tabular}

Samples were tested in triplicate on three consecutive days.

\section{Macroscopic and microscopic evaluation of colonic damage}

Macroscopic and microscopic evaluations of the colonic damage are shown in Table II. Severe inflammation, ulceration, adhesion and wall thickening were induced by intracolonic administration of TNBS/ethanol in the control group in comparison to colons of the sham as normal group. Macroscopic scores were significantly improved by dexamethasone in colitic rats. Colonic damage decreased after administration of both gall extract and gall powder.

Light microscopic examination of the colon in the sham group showed normal histology and revealed a regular mucosal layer with intact epithelial surface (Figure $2 \mathrm{~A}$ ).

Animals receiving TNBS showed multifocal degenerative changes in the epithelial lining and areas of necrosis, extensive mucosal and sub-mucosal damage with congested blood vessels, edema and hemorrhages along with extensive infiltration of inflammatory cells (Figures 2 B-D). Histological analysis of the colonic specimens from the gall powder group revealed a pronounced restoration of the epithelial cell layer in comparison to untreated rats. There was mild cellular infiltration in the sub-mucosa and only a maximum of $25 \%$ of the epithelium was affected in contrast to the comprehensive ulceration observed in non-treated animals (Figure $2 \mathrm{E}$ ). Treatment with extract orally showed a complete protective effect against TNBS-induced colonic injury (Figure 2 F). The mucosa showed intact epithelium, no ulceration, no congestion and no edema (Figure 2 F).

\section{Colonic TNF- $\alpha$ level}

The inflammatory condition caused a significant increase in TNF- $\alpha$ in the control group when compared to the sham group $(p<0.01)$. TNF- $\alpha$ significantly decreased in gall extract and gall powder groups in comparison to controls (Figure 3).

\section{Colonic IL-1 $\beta$ levels}

IL-1 $\beta$ level was higher in the control group as compared to shams $(p<0.01)$. The level of IL-1 $\beta$ in the extract group was lower as compared to con-
Table II. Extent of colonic damage according to macroscopic and microscopic scores

\begin{tabular}{|lcc|}
\hline Groups & $\begin{array}{c}\text { Macroscopic score } \\
\text { mean } \pm \text { SEM, } \\
\text { median, min-max }\end{array}$ & $\begin{array}{c}\text { Microscopic score } \\
\text { mean } \pm \text { SEM, } \\
\text { median, min-max }\end{array}$ \\
\hline Sham & $0.0 \pm 0.0$, & $0.0 \pm 0.0$, \\
$0,0.0-0.0$ & $0,0.0-0.0$ \\
\hline Control & $5.0 \pm 1.05$, & $3.57 \pm 0.30^{\mathrm{a}}$, \\
& $6,2.0-7.0$ & $4,2.0-4.0$ \\
\hline Dexa & $0.66 \pm 0.33^{\mathrm{b}}$, & $0.83 \pm 0.30^{\mathrm{b}}$, \\
& $0.5,0.0-2.0$ & $1.0,0.0-2.0$ \\
\hline Gall & $1.0 \pm 0.32)^{\mathrm{b}}$, & $1.71 \pm 0.29^{\mathrm{a}, \mathrm{b}}$, \\
extract & $1,0.0-2.0$ & $2,1.0-3.0$ \\
\hline Gall & $1.2 \pm 2.0^{\mathrm{b}}$, & $2.42 \pm 0.36^{\mathrm{a}, \mathrm{b}, \mathrm{c}}$, \\
powder & $1,1.0-2.0$ & $2,1.0-4.0$ \\
\hline
\end{tabular}

${ }^{a}$ Significantly different from Sham group at $p<0.01 .{ }^{b}$ Significantly different from control group at $p<0.01$. cSignificantly different from Dexa group at $p<0.01$.

trols. Values in extract were near the Dexa group and close to the sham group (Figure 4).

\section{Colonic total antioxidant power as FRAP}

Colonic damage and inflammation caused a significant reduction in the FRAP value of the control group when compared to normal rats in the sham group $(p<0.01)$. The FRAP values were significantly elevated following administration of gall extract and gall powder (Figure 5).

\section{Colonic lipid peroxidation level as TBARS}

Induction of colitis caused a significant increase in the TBARS value $(p<0.01)$ as compared to shams. The TBARS decreased in the extract-treated animals in comparison to controls (Figure 6).

\section{Colonic MPO activity}

The MPO activity in the colitis group was significantly higher than the sham group ( $p<0.01)$. Treatment with both gall extract and gall powder reduced MPO activity as compared to the control group (Figure 7 )

\section{Discussion}

The outcome of the present study indicated that $Q$. brantii Lindl. has a protective effect on 

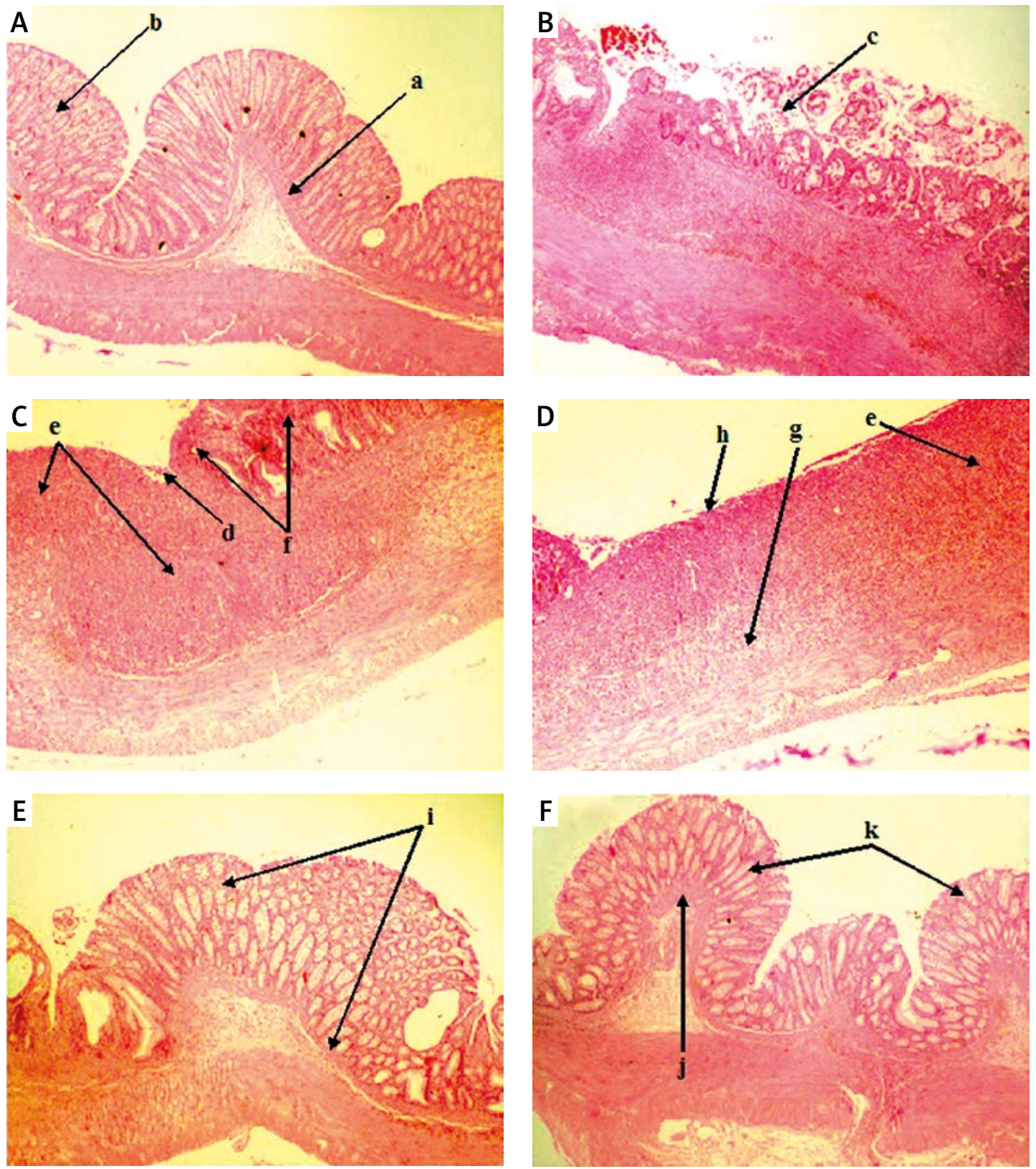

Figure 2. Photomicrograph of colon trans-mural histology in sham and experimental groups. $H+E$ : hematoxylin and eosin stain. Original magnification: 100x. A - No histological modification is present in the sham animals and a regular mucosal layer (a) with intact epithelial surface (b) is seen. In the colitis group (B, C and D), multifocal degeneration and necrosis of epithelium (c, d), massive infiltration of inflammatory cells in the mucosa and sub-mucosa (e), obvious hemorrhages and congestion ( $\mathrm{f}$ ), edema (g), and crypt abscesses (h) are observed. Treatment with gall powder $(\mathrm{E})$ reduced the morphological alteration showing protection of mucosal and epithelium architecture (i) with some focal areas of epithelial necrosis and mild inflammatory cell infiltration. No abnormality is seen in the extract-treated group (F). Treatment with Quercus brantii completely protected the morphological alteration associated with TNBS administration. Note the intact mucosal layer (j) and epithelial surface ( $k$ )

TNBS-induced colitis via suppression of free radicals, toxic stress and pro-inflammatory condition. This plant in combination with other plants has been used in a traditional Iranian medicine clinic located in the TUMS campus for IBD patients and had shown good effects. To the best of our knowledge, this is the first study showing the benefit of $Q$. brantii in a murine model of experimental colitis.
Quercus has been used for centuries in Asian countries for treatment of inflammatory conditions and microbial infections [48]. Water-methanolic extract of Quercus galls has a large amount of tannins. Regarding the role of microbes and the oxidative inflammatory process in induction of colitis, the first thing that comes to mind is to relate the benefit of Quercus to its antibacterial [29-34], antioxidant $[35,36]$, and anti-inflammatory properties [24]. 


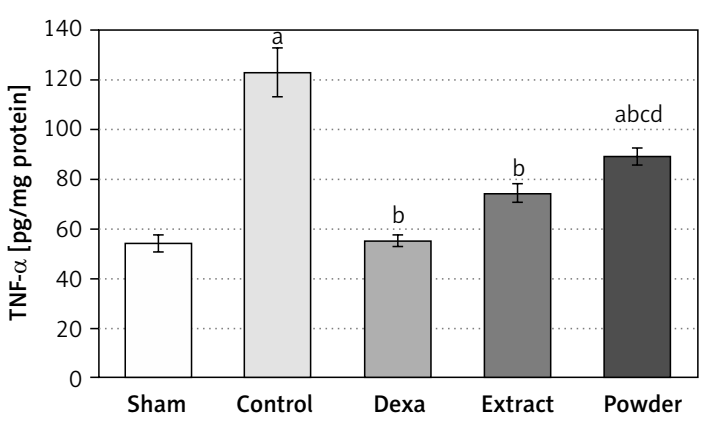

Figure 3. Tumor necrosis factor- $\alpha$ level in colon

Values are mean \pm SEM. ${ }^{a}$ Significantly different from sham group at $p<0.01$. ' Significantly different from control group at $p<0.01$. 'Significantly different from Dexa group at $p<0.01 .{ }^{d}$ Significantly different from extract group at $p<0.01$.

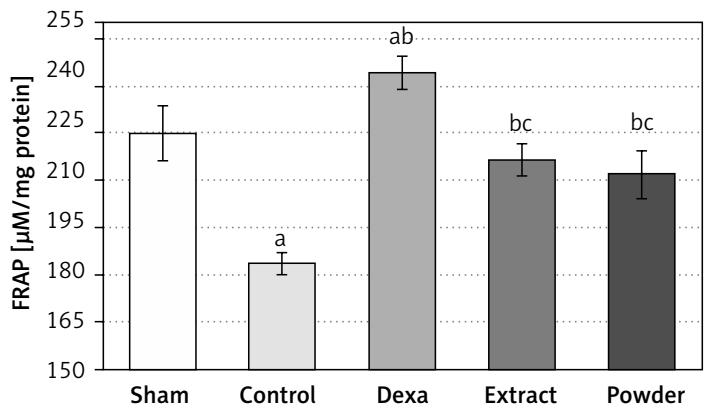

Figure 5. Ferric reducing antioxidant power of colon

Values are mean \pm SEM. ${ }^{a}$ Significantly different from sham group at $p<0.01$. ' Significantly different from control group at $p<0.01$. 'Significantly different from Dexa group at $p<0.01$.

Quercus brantii improved TNBS-induced colitis by inhibition of the synthesis or release of inflammatory mediators, reduction of oxidative stress and maintaining antioxidant power status. These results clearly indicate that administration of $Q$. brantii reduces LPO and MPO (markers of OS) and increases a marker of antioxidant potential in TNBS-induced colitis. All of the present protective effects of $Q$. brantii were consistent with histological evidence showing significant improvement in microscopic characteristics of the colon when compared to the colitis group.

Among several models of experimental colitis, TNBS-induced colitis is one of the reliable models. This model is very useful in studying gut inflammation, cytokine secretion patterns, cell adhesion and immunotherapy. In this manner, ethanol breaks the mucosal barrier, and TNBS acts as a hapten, and its administration induces a delayed-type of hypersensitivity reaction similar to chronic colitis in humans [49].

It has been determined that pro-inflammatory cytokines such as IL-1 $\beta$ and TNF- $\alpha$ rise in primary stages of colitis [50]. IL-1 $\beta$ and TNF- $\alpha$ are produced by monocytes and tissue macrophages and

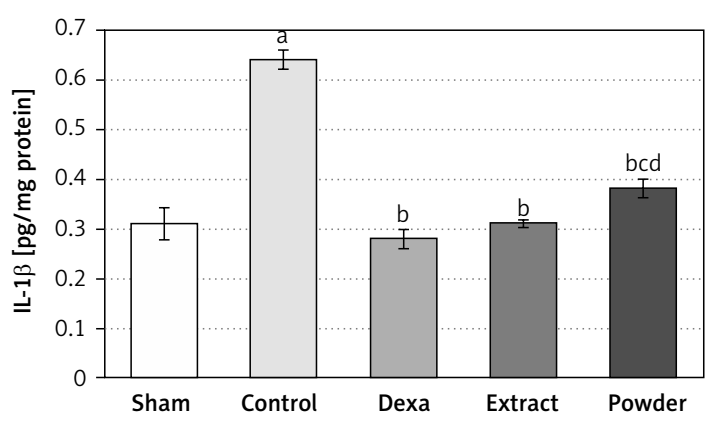

Figure 4. Interleukin-1 $\beta$ level in colon

Values are mean \pm SEM. ${ }^{a}$ Significantly different from sham group at $p<0.01$. ' Significantly different from control group at $p<0.01$. 'Significantly different from Dexa group at $p<0.01$. 'Significantly different from extract group at $p<0.01$.

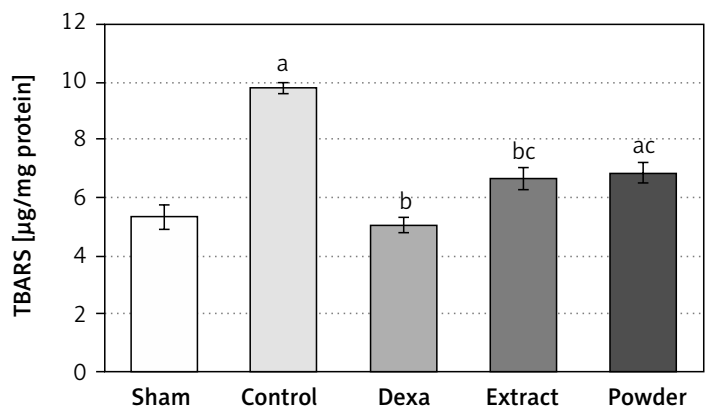

Figure 6. Lipid peroxidation as TBARS in colon

Values are mean \pm SEM. ${ }^{a}$ Significantly different from sham group at $p<0.01$. ' Significantly different from control group at $p<0.01$. 'Significantly different from Dexa group at $p<0.01$.

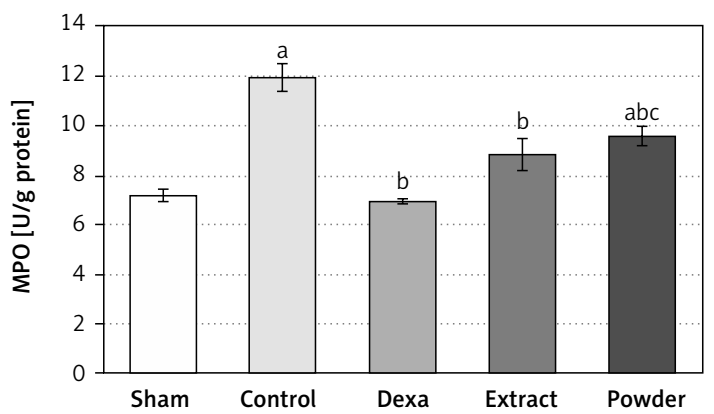

Figure 7. Myeloperoxidase (MPO) activity in colon

Values are mean \pm SEM. ${ }^{a}$ Significantly different from sham group at $p<0.01$. 'bignificantly different from control group at $p<0.01$. 'Significantly different from Dexa group at $p<0.01$.

have a regulatory effect on some inflammatory processes involving genes. TNF- $\alpha$ is a potent component of apoptosis that activates NF-kB too [51]. It has an important role in pathogenesis of IBD and a new strategy for colitis treatment is blocking TNF- $\alpha$ activity.

The MPO and LPO are markers of free radical damage to intestinal cells. Free radicals are released by phagocytes and to a lesser extent by 
eosinophils, lymphocytes and fibroblasts during toxic stress. According to our results, MPO activity significantly decreased after consumption of $Q$. brantii. In this regard, it has been well documented that $Q$. brantii is able to reduce inflammation via secretion of destructive agents such as MPO resulting from penetration of neutrophils to the inflammation site [17]. Interestingly, the anti-inflammatory effect of most medicinal plants which have been used in traditional medicine relates to their antioxidant characteristics $[6,52]$. The results of the TBARS assay in colonic tissue show that $Q$. brantii reduces colonic damage by down-regulating LPO. Quercus could increase the anti-oxidant power of colonic tissue in comparison to controls as expected; this property may relate to the potential of Quercus gall to scavenge free radicals and enhance the activity of anti-oxidant enzyme. Galls of $Q$. infectoria (another species) have been shown to contain a large amount of polyphenols. High performance thin layer chromatography (HPTLC) analysis of extract suggested that it contains $19.925 \%$ tannic acid (TA) and $8.75 \%$ gallic acid (GA) [35]. By measuring total phenolic content as the main components of galls of Quercus spp. [25], in our study, it was demonstrated that $88.43 \pm 7.23 \%$ of dry gall (Table I) was composed of phenolics, which are one of the main components responsible for radical scavenging activity of plants [53]. Quantification of free gallic acid as one of the present phenolic compounds in galls of Quercus spp. revealed that it constitutes one of the main components of the gall (3.74\% of dry weight). In previous studies, the antioxidant and pro-oxidant activity of gallic acid, its derivatives and metabolites have been shown [54, 55].

Regarding the pathogenesis of colitis, two parameters are more important than others: microbes and inflammation [56-58]. Therefore, we can conclude that $Q$. brantii probably acts through its anti-inflammatory and antimicrobial effects. Quercus brantii induced antioxidants especially via inhibition of inflammatory cytokines such as TNF- $\alpha, I L-1 \beta$ and MPO. It is notable that in macroscopic, microscopic and enzymatic evaluation, positive results with the gall extract surpassed those of gall powder. This might relate to better release of effective compounds of extract in comparison to crude plant powder, which needs more time. In the extract form, the treatment process is facilitated by decreasing the release stage of tannins.

Polyphenols including gallic acid are responsible for the main antioxidant and anti-inflammatory effect of galls of $Q$. brantii.

In view of the fact that antioxidants and anticytokines usually prevent complications or further progress of the disease, it is strongly recommended to examine useful medicinal herbs like Q. brantii in the clinic concurrent with standard therapies to determine their benefit in patients with colitis.

\section{Acknowledgments}

Mahnaz Khanavi and Mansoureh Sabbagh-Bani-Azad contributed equally as the first author.

This study was partly supported by a grant from TUMS. The authors wish to thank Dr. Gholamreza Amin for recognizing the species of Quercus.

\section{References}

1. Jahanshahi G, Motavasel V, Rezaie A, Hashtroudi AA, Daryani NE, Abdollahi M. Alterations in antioxidant power and levels of epidermal growth factor and nitric oxide in saliva of patients with inflammatory bowel diseases. Dig Dis Sci 2004; 49: 1752-7.

2. Rezaie A, Ghorbani F, Eshghtork A, et al. Alterations in salivary antioxidants, nitric oxide, and transforming growth factor-betal in relation to disease activity in Crohn's disease patients. Ann N Y Acad Sci 2006; 1091: 110-22.

3. Rezaie A, Khalaj S, Shabihkhani M, et al. Study on the correlations among disease activity index and salivary transforming growth factor-beta 1 and nitric oxide in ulcerative colitis patients. Ann N Y Acad Sci 2007; 1095: 305-14.

4. Nikfar S, Rahimi R, Rezaie A, Abdollahi M. A meta-Analysis of the efficacy of sulfasalazine in comparison with 5 -aminosalicylates in the induction of improvement and maintenance of remission in patients with ulcerative colitis. Dig Dis Sci 2009; 54: 1157-70.

5. Rahimi R, Nikfar S, Rezaie A, Abdollahi M. Comparison of mesalazine and balsalazide in induction and maintenance of remission in patients with ulcerative colitis: a meta-analysis. Dig Dis Sci 2009; 54: 712-21.

6. Rahimi R, Nikfar S, Abdollahi M. Meta-analysis technique confirms the effectiveness of anti-TNF-alpha in the management of active ulcerative colitis when administered in combination with corticosteroids. Med Sci Monit 2007; 13: PI13-8.

7. Rahimi R, Nikfar S, Abdollahi M. Do anti-tumor necrosis factors induce response and remission in patients with acute refractory Crohn's disease? A systematic meta-analysis of controlled clinical trials. Biomed Pharmacother 2007; 61: 75-80.

8. Nikfar S, Ehteshami-Afshar S, Abdollahi M. A systematic review and meta-analysis of the efficacy and adverse events of infliximab in comparison to corticosteroids and placebo in active ulcerative colitis. Int J Pharmacol 2011; 7: 325-32.

9. Rezaie A, Taghavi Bayat B, Abdollahi M. Biologic management of fistulizing Crohn's disease. Int J Pharmacol 2005; 1: 17-24.

10. Nikfar S, Mirfazaelian H, Abdollahi M. Efficacy and tolerability of immunoregulators and antibiotics in fistulizing Crohn's disease: a systematic review and meta-analysis of placebo-controlled trials. Curr Pharm Des 2010; 16: 3684-98.

11. Triantafillidis JK, Merikas E, Georgopoulos F. Current and emerging drugs for the treatment of inflammatory bowel disease. Drug Des Devel Ther 2011; 5: 185-210. 
12. Rezaie A, Parker RD, Abdollahi M. Oxidative stress and pathogenesis of inflammatory bowel disease: an epiphenomenon or the cause? Dig Dis Sci 2007; 52: 2015-21.

13. Rahimi R, Nikfar S, Rezaie A, Abdollahi M. A meta-analysis of broad spectrum antibiotic therapy in patients with active Crohn's disease. Clin Ther 2006; 28: 1983-8.

14. Rahimi R, Nikfar S, Rezaie A, Abdollahi M. A meta-analysis of antibiotic therapy for active ulcerative colitis. Dig Dis Sci 2007; 52: 2920-5.

15. Nikfar S, Darvish-Damavandi M, Abdollahi M. A review and meta-analysis of the efficacy of antibiotics and probiotics in management of pouchitis. Int J Pharmacol 2010; 6: 826-35.

16. Nikfar S, Ehteshami-Ashar S, Rahimi R, Abdollahi M. Systematic review and meta-analysis of the efficacy and tolerability of nicotine preparations in active ulcerative colitis. Clin Ther 2010; 32: 2304-15.

17. Hosseini-Tabatabaei A, Abdollahi M. Potassium channel openers and improvement of toxic stress: do they have role in the management of inflammatory bowel disease? Inflamm Allergy Drug Targets 2008; 7: 129-35.

18. Salari P, Abdollahi M. Current opinion in the pharmaceu tical management of irritable and inflammatory bowel diseases: role of ATP. Recent Pat Endocr Metab Immune Drug Discov 2009; 3: 69-75.

19. Khoshakhlagh P, Bahrololoumi-Shapourabadi M, Mohammadirad A, Ashtaral-Nakhai L, Minaie B, Abdollahi M Beneficial effect of phosphodiesterase-5 inhibitor in experimental inflammatory bowel disease; molecular evidence for involvement of oxidative stress. Toxicol Mech Methods 2007; 17: 281-8.

20. Salari-Sharif P, Abdollahi M. Phosphodiesterase 4 inhibitors in inflammatory bowel disease: a comprehensive review. Curr Pharm Des 2010; 16: 3661-7.

21. Rahimi R, Ghiasi S, Azimi H, Fakhari S, Abdollahi M. A review of the herbal phosphodiesterase inhibitors: future perspective of new drugs. Cytokine 2010; 49: 123-9.

22. Rahimi R, Mozaffari S, Abdollahi M. On the use of herbal medicines in management of inflammatory bowel diseases: a systematic review of animal and human studies. Dig Dis Sci 2009; 54: 471-80.

23. Rahimi R, Shams-Ardekani MR, Abdollahi M. A review of the efficacy of traditional Iranian medicine for inflammatory bowel disease. World J Gastroenterol 2010; 16 : 4504-14.

24. Samulsson RG. Drugs of natural origine: a text book of pharmacognosy. Swedish Pharmaceutical Press, Stockholm 1999; 86.

25. Kaur G, Hamid H, Ali A, Alam MS, Athar M. Antiinflammatory evaluation of alcoholic extract of galls of Quercus infectoria. J Ethnopharmacol 2004; 90: 285-92.

26. Aghili MH. Makhzan al-advieh (Persian). Tehran University Press, Tehran 2009; 611-2.

27. Dar MS, Ikram M, Fakouhi T. Pharmacology of Quercus infectoria. J Pharm Sci 1976; 65: 1791-94

28. Hwang JK, Kong TW, Baek NI, Pyun YR. alpha-Glycosidase inhibitory activity of hexagalloylglucose from the galls of Quercus infectoria. Planta Med 2000; 66: 273-4.

29. Sawangjaroen N, Sawangjaroen K, Poonpanang P. Effects of Piper longum fruit, Piper sarmentosum root and Quercus infectoria nut gall on caecal amoebiasis in mice. J Ethnopharmacol 2004; 91: 357-60.

30. Suwalak S, Voravuthikunchai SP. Morphological and ultrastructural changes in the cell structure of enterohaemorrhagic Escherichia coli 0157:H7 following treatment with Quercus infectoria nut galls. J Electron Microsc (Tokyo) 2009; 58: 315-20.
31. Voravuthikunchai SP, Suwalak S. Antibacterial activities of semipurified fractions of Quercus infectoria against enterohemorrhagic Escherichia coli 0157:H7 and its verocytotoxin production. J Food Prot 2008; 71: 1223-7.

32. Vermani A; Navneet; Prabhat. Screening of Ouercus infectoria gall extracts as anti-bacterial agents against dental pathogens. Indian J Dent Res 2009; 20: 337-39.

33. Berahou A, Auhmani A, Fdil N, Benharref A, Jana M, Gadhi CA. Antibacterial activity of Quercus ilex bark's extracts. J Ethnopharmacol 2007; 112: 426-9.

34. Mandana Rodriguez A, Gausa Rull P. Therapeutic effects of Quercus extract in urolithiasis. Arch Esp Urol 1980; 33: 205-26.

35. Kaur G, Athar M, Alam MS. Quercus infectoria galls possess antioxidant activity and abrogates oxidative stress-induced functional alterations in murine macrophages. Chem Biol Interact 2008; 171: 272-82.

36. Hamid H, Kaur G, Abdullah T, Ali M, Athar M, Sarwar Alam M. Two new compounds from the Galls of Quercus infectoria with nitric oxide and superoxide inhibiting ability. Pharm Biol 2005; 43: 317-23.

37. Sarker SD, Latif Z, Gray Al. Natural products isolation. Humana Press, New Jersey (NJ) 2006.

38. Miliauskas G, Venskutonis PR, Van Beek TA. Screening of radical scavenging activity of some medicinal and aromatic plant extracts. Food Chem 2004; 85: 231-7.

39. Inoue $\mathrm{KH}$, Hagerman AE. Determination of gallotannin with rhodanine. Anal Biochem 1988; 169: 363-9.

40. Leblanc GA. Acute toxicology. In: A textbook of modern toxicology. Hodgson E (ed.). John Wiley \& Sons, New Jersey 2004; 215-7.

41. Abdolghaffari A, Baghaei A, Moayer F, et al. On the benefit of Teucrium in murine colitis through improvement of toxic inflammatory mediators. Hum Exp Toxicol 2010; 29: 287-95.

42. Ghazanfari G, Minaie B, Yasa N, et al. Biochemical and histopathological evidences for beneficial effects of satureja khuzestanica jamzad essential oil on the mouse model of inflammatory bowel diseases. Toxicol Mech Methods 2006; 16: 365-72.

43. Baghaei A, Esmaily $H$, Abdolghaffari $A H$, Baeeri $M$, Gharibdoost F, Abdollahi M. Efficacy of Setarud (IMod), a novel drug with potent anti-toxic stress potential in rat inflammatory bowel disease and comparison with dexamethasone and infliximab. Indian J Biochem Biophys 2010; 47: 219-26.

44. Astaneie F, Afshari M, Mojtahedi A, et al. Total antioxidant capacity and levels of epidermal growth factor and nitric oxide in blood and saliva of insulin-dependent diabetic patients. Arch Med Res 2005; 36: 376-81.

45. Krawisz JE, Sharon P, Stenson WF. Qualitative assay for acute intestinal inflammation based on myeloperoxidase activity. Gastroenterology 1984; 87: 1344-50.

46. Nakhai LA, Mohammadirad A, Yasa N, et al. Benefits of Zataria multiflora Boiss in experimental model of mouse inflammatory bowel disease. Evid Based Complement Alternat Med 2007; 4: 43-50.

47. Bradford MM. A rapid and sensitive method for the quantitation of microgram quantities of protein utilizing the principle of protein-dye binding. Anal Biochem 1976; 72: 248-54.

48. Anonymous. The Wealth of India: a dictionary of Indian raw materials and industrial products. 13 volume series. Publications Information Directorate (CSIR), New Delhi $1995 ; 351$.

49. Wirtz S, Neufert C, Weigmann B, Neurath MF. Chemically induced mouse models of intestinal inflammation. Nat Protoc 2007; 2: 541-6. 
M. Khanavi, M. Sabbagh-Bani-Azad, A.H. Abdolghaffari, M. Vazirian, I. Isazadeh, M.A. Rezvanfar, M. Baeeri, A. Mohammadirad, R. Rahimi, M.R. Shams-Ardekani, M. Abdollahi

50. Miroliaee AE, Esmaily $H$, Vaziri-Bami A, Baeeri M, Shahverdi $A R$, Abdollahi $M$. Amelioration of experimental colitis by a novel nanoselenium-silymarin mixture. Toxicol Mech Methods 2011; 21: 200-8.

51. Esmaily H, Vaziri-Bami A, Miroliaee AE, Baeeri M, Abdollahi M. The correlation between NF-kappaB inhibition and disease activity by coadministration of silibinin and ursodeoxycholic acid in experimental colitis. Fundam Clin Pharmacol 2011; 25: 723-33.

52. Hasani-Ranjbar S, Larijani B, Abdollahi M. A systematic review of the potential herbal sources of future drugs effective in oxidant-related diseases. Inflamm Allergy Drug Targets 2009; 8: 2-10.

53. Bungert K, Erichner K. Radical scavenging and antioxidative properties of phenolic compounds in relation to their chemical structure. In: Caffeinated beverages. Parliament TH, Ho CH, Schieberle P (eds). American Chemical Society, Washington DC 2000; 119-34.

54. Yen GC, Duh PD, Tsai HL. Antioxidant and pro-oxidant properties of ascorbic acid and gallic acid. Food Chem 2002; 79: 307-13.

55. Yasuda T, Inaba A, Ohmori M, Endo T, Kubo S, Ohsawa K. Urinary metabolites of gallic acid in rats and their radical scavenging activity on 1,1-diphenyl-2-picrylhydrazyl radical. J Nat Prod 2000; 63: 1444-6.

56. Ehteshami-Afshar S, Nikfar S, Rezaie A, Abdollahi M. A systematic review and meta-analysis of the effects of infliximab on the rate of colectomy and post-operative complications in patients with inflammatory bowel disease. Arch Med Sci 2011; 7: 1000-12.

57. Rezaie A, Nikfar S, Abdollahi M. The place of antibiotics in management of irritable bowel syndrome: a systematic review and meta-analysis. Arch Med Sci 2010; 6: 49-55.

58. Hosseini A, Nikfar S, Abdollahi M. Are probiotics effective in management of irritable bowel syndrome? Arch Med Sci 2012; 8: 403-5. 